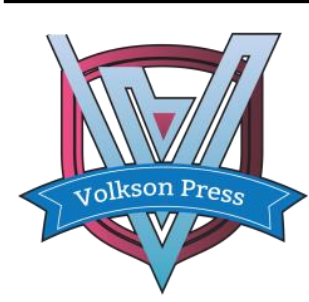

\title{
Research on the Efficiency of Cultural Manufacturing Industry in China Based on DEA-Malmuquist
}

\author{
Ping Gu1, Zili Chen 2 * Cheng Chen3 \\ 1,2,3 School of Economics and Management, Jiangsu University of Science and Technology, China \\ *czlstudy@163.com
}

This is an open access article distributed under the Creative Commons Attribution License, which permits unrestricted use, distribution, and reproduction in any medium, provided the original work is properly cited.

\section{ARTICLE DETAILS}

\section{Article History:}

Received 02 october 2017

Accepted 06 october 2017

Available online 11 october 2017

Keywords:

DEA; Malmquist Model; Cultural

Manufacturing Industry;

Efficiency.

\section{ABSTRACT}

The development of Cultural Manufacturing Industry is an important ingredient in cultural industry. And improving the efficiency of Culture Manufacturing Industry also helps promote the development of cultural industry. This paper builds up the basic framework for the evaluation system of Cultural Manufacturing Industry efficiency in China using panel data of 31 provinces during 2012-2014. In this context, Data Envelopment Analysis (DEA) method is used to measure the efficiency of every provincial Cultural Manufacturing Industry. The results show that the development of every provincial Cultural Manufacturing Industry is not balanced, with great space to improve. Technical progress has also been the decisive factor to the growth of Cultural Manufacturing Industry efficiency. With such a sound basis, some proposals regarding further development of Cultural Manufacturing Industry are concluded.

\section{Introduction}

Cultural industries, because of its high technology, high value, low pollution, low power consumption, became the inevitable part of modern economy. In accordance with industry, Cultural industry can be divided into three categories: Cultural Manufacturing Industry, Cultural Enterprises of Service Industry, Cultural Wholesale and Retail Trades Enterprises. According to statistics, China's Cultural industry value added has grown from 1.1052 trillion yuan in 2010up to 2015's 2.5829 trillion yuan and the proportion of Cultural Manufacturing Industry value added has increased form $2.15 \%$ in 2010 to $3.82 \%$ in 2015. National bureau of statistics released in 2016 Cultural Manufacturing Industry value is 1.1053 trillion yuan, an increase of 8.4 percent over the previous year. Cultural Manufacturing Industry value added account for $40.6 \%$ of culture and related industry[1]. With China's rapid development of national economy, Cultural Manufacturing Industry has a more and more important position in our industrial structure. This industry not only impacts the efficiency of Cultural industry, but it impacts the steady growth of our economy. The unbalanced region economy development has become the key problem that affects the efficiency of Cultural Manufacturing Industry[2]. Therefore, this paper is to set up an assessment indicator system, which is suitable to evaluate the efficiency of Cultural Manufacturing Industry and DEA-Malmquist index method is used to measure the efficiency of every provincial Cultural Manufacturing Industry.

\section{Literature review}

Cultural Manufacturing Industry is a conception been put forward lately in China[2]. Cultural Manufacturing Industry is in the cross field of Cultural Industry and Manufacturing Industry and characterizes Cultural industry and Manufacturing Industry. At present, most of the scholars' research on the cultural manufacturing industry is limited to the level of policy theory and Cultural Industry. However, there is very little research about the efficiency of Cultural Manufacturing Industry. Scholars abroad pay their attention on Cultural industry and cultural products. Yaveroglu I S and Donthu N (2002) examine cultural influences on the diffusion of new products[3]. Avan, Hemant(2002) found that culture play an important role in the process of new product development[4]. Richard and Anan (2004) introduce six facets of production (technology, law and regulation, industry structure, organization structure, occupational careers, and market) and study the application of cultural products[5]. Timothy (2007) examines the recent changes in the culture industry and demographics that permitted a formerly underground music to enter the mainstream[6]. Jeremy (2014) analyzes the influence of rent and policy on culture industry[7]. But most of the scholars in China focus their studies on the innovation efficiency. Han Donglin, Yuan Qian, Li Chunying (2016) employs DEA to evaluate the Cultural Manufacturing Industry innovation efficiency of the central region of China during 2012-2014, the result of study showed that the TFP of the central region is higher than the average level of the eastern regions[8]. Mao Ruiqiong (2016) uses Stochastic Frontier Analysis to evaluate the Cultural Manufacturing Industry innovation efficiency of 29 provinces and municipalities of China during 2010-2014, The results demonstrate that the innovation efficiency isn't high in China[9].

\section{Methodologies}

\subsection{Data Envelopment Analysis (DEA)}

Data Envelopment Analysis (DEA) is a method of evaluating units productivity which have same resources, it is also a Nonparametric method and was first put forward by Charnes, Cooper and Rhodes in1978[9]. Each evaluation object can be regarded as a decision unit. Each decision unit has a system with multi inputs and outputs. And from the view of input and output, DEA model can be used to measure the relative effectiveness of decision making units (DMUs). As a relatively simple method, DEA is used widely. Given the extent of Cultural Manufacturing Industry, the BCC model under variable returns to scale is more suitable for the analysis of the efficiency. The technical efficiency (TF) can be decomposed into pure technical efficiency (PTE) and scale efficiency (SE) I.e., TE $=$ PTE * SE[11]. By increasing the constraints on the weight $\lambda$, the BCC model based on Variable Return Scale is established as follow:

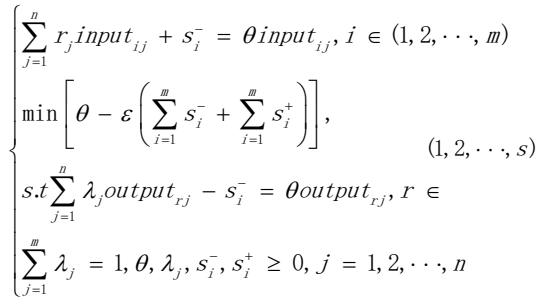


$\mathrm{m}$ stands for input factors, $\mathrm{s}$ stands for output factors, $\lambda_{j}$ stands for the input or output of index weight,

$\theta$ stands for relative efficiency, $s_{i}^{-}, s_{i}^{+}$represents corresponding slack variable. By comparing the

solution, the efficiency of decision making units(DMUs) were measured, then reach the goal of evaluating the efficiency of Cultural Manufacturing Industry in China.

\subsection{Malmquist index model}

DEA can't analyze the efficiency change of the Chinese Cultural Manufacturing Industry in different years, and Malmquist index model can effectively make up for the disadvantage of DEA. Through this method, Technical Efficiency Change can be decomposed into Technical Efficiency Change and Scale Efficiency Change.

$$
\begin{aligned}
& S^{t}\left(x^{t}, y^{t}\right), S^{t+1}\left(x^{t+1}, y^{t+1}\right) \text { as distance function, Malmquist index can be decomposed into: } \\
& M\left(x^{t}, y^{t}, x^{t+1}, y^{t+1}\right)=\frac{S^{t+1}\left(x^{t+1}, y^{t+1}\right)}{S^{t}\left(x^{t}, y^{t}\right)} \times\left[\frac{S^{t}\left(x^{t}, y^{t}\right)}{S^{t+1}\left(x^{t}, y^{t}\right)} \times \frac{S^{t}\left(x^{t+1}, y^{t+1}\right)}{S^{t+1}\left(x^{t+1}, y^{t+1}\right)}\right]^{1 / 2} \times \\
& {\left[\frac{S^{t}\left(x^{t+1}, y^{t+1}\right) / S^{t+1} x^{t+1}, y}{S^{t}\left(x^{t}, y^{t}\right) / S^{t}\left(x^{t}, y^{t}\right)} \times \frac{\left.S^{t+1}\left(x^{t+1}, y^{t+1}\right) / S^{t+1}\left(x^{t+1},\right]^{t+1}\right)}{S^{t+1}\left(x^{t}, y^{t}\right) / S^{t+1}\left(x^{t}, y^{t}\right)} \quad \text { Pech } \times \text { Techch } \times\right. \text { Sech }}
\end{aligned}
$$

\section{Empirical Analysis}

\subsection{Indexes Selection}

Based on the research from relevant scholars and the availability of data, the evaluation indexes of Chinese Cultural Manufacturing Industry were selected. In terms of input, labor and capital factors were are considered. The number of employees and Total assets are usually seen as outputs, total industrial output value and operating income are seen as outputs in this paper (see table 2.1).

Table 2.1 the analysis indicator of China's Cultural Manufacturing Industry

\begin{tabular}{cc}
\hline Inputs & $\begin{array}{c}\text { The number of employees } \\
\text { Total assets } \\
\text { total industrial output value } \\
\text { operating income }\end{array}$ \\
outputs & \\
\hline
\end{tabular}

\subsection{Data Sources}

This paper selects China's Cultural Manufacturing Industries as the samples, In order to guarantees the objective and accurate evaluation, the data this paper used is based on Chinese Cultural and relevant industries Statistical yearbooks during 2013-2015,

\section{Empirical Analyses}

In general, inputs happen before outputs and can be easier adjusted in practice. This paper select DEA-BCC model as the method of evaluation, applies deap2.1 measuring the efficiency of every provincial Cultural Manufacturing Industry during from 2013 to 2014, the results are shown in Table 4.1 .

Tab.4.1 Input-output efficiency value of the cultural Industrial Enterprises during 2012-2014

\begin{tabular}{cccc}
\hline Region & $\mathbf{2 0 1 2}$ & $\mathbf{2 0 1 3}$ & $\mathbf{2 0 1 4}$ \\
\hline Beijing & 0.45 & 0.46 & 0.371 \\
Tianjin & 1 & 1 & 0.788 \\
Hebei & 0.78 & 0.858 & 0.699 \\
Shaanxi & 0.38 & 0.395 & 0.327 \\
Inner Mongolia & 1 & 1 & 1 \\
Liaoning & 0.89 & 0.864 & 0.557 \\
Jilin & 0.63 & 0.742 & 0.575 \\
Heilongjiang & 0.57 & 0.848 & 0.912 \\
Shanghai & 0.8 & 0.859 & 0.61 \\
Jiangsu & 0.74 & 0.784 & 0.613 \\
Zhejiang & 0.49 & 0.528 & 0.404 \\
Anhui & 0.76 & 0.75 & 0.625 \\
Fujian & 0.77 & 0.792 & 0.793 \\
Jiangxi & 0.96 & 0.969 & 0.904 \\
Shandong & 0.8 & 0.883 & 0.677 \\
Henan & 0.7 & 0.726 & 0.635 \\
Hubei & 0.71 & 0.868 & 0.756 \\
Hunan & 1 & 1 & 1 \\
Guangdong & 0.69 & 0.712 & 0.653 \\
Guangxi & 0.63 & 0.683 & 0.724 \\
Hainan & 0.76 & 0.907 & 0.999 \\
Chongqing & 0.73 & 0.609 & 0.501 \\
Sichuan & 0.54 & 0.639 & 0.597 \\
Guizhou & 0.86 & 1 & 0.816 \\
Yunnan & 0.53 & 0.622 & 0.499 \\
Xizang & 0.31 & 0.347 & 0.23 \\
\hline
\end{tabular}

\begin{tabular}{cccc}
\hline Con Tab.4.1 & & & \\
Shaanxi & 0.56 & 0.675 & 0.617 \\
Gansu & 0.36 & 0.324 & 0.311 \\
Qinghai & 0.65 & 0.389 & 0.45 \\
Ningxia & 0.21 & 0.196 & 0.177 \\
Sinkiang & 0.52 & 0.523 & 0.425 \\
Average score of eastern provinces & 0.728 & 0.778 & 0.661 \\
Average score of Central provinces & 0.826 & 0.863 & 0.784 \\
Average score of Western provinces & 0.575 & 0.584 & 0.529 \\
Average score of Northeast provinces & 0.697 & 0.818 & 0.681 \\
Average & 0.670 & 0.708 & 0.621 \\
\hline
\end{tabular}

First, from the aspect of time window, we can find that the average efficiency cores of 31 provinces' Cultural Manufacturing Industries are all less than 1; this shows that each listed Cultural Manufacturing Industries is DEA inefficient. At the same time, the average efficiency score of China's Cultural Manufacturing Industries is between 0.62 and 0.708 . The average efficiency score in 2014 is the lowest. Second, from a regional view, the efficiency of china's Cultural Manufacturing Industries has greater diversity among various regions, which was caused by the imbalance of regional economic development. The rank order of regional efficiency in 2012 is Central provinces, eastern provinces, Northeast provinces, then Western provinces; the rank order of regional efficiency in 2013 is Northeast provinces, Central provinces, eastern provinces, then Western provinces; the rank order of regional efficiency in 2014 is Central provinces, Northeast provinces, eastern provinces, and then Western provinces. And from 2013 to 2014, the efficiency of eastern provinces is the lowest. We evaluate the efficiency of china's Cultural Manufacturing Industries above using DEA method, but this method calculates the efficiency of Cultural Manufacturing Industries from static goniometer, namely horizontal comparison of the efficiency in the same period of different Cultural Manufacturing Industries which isn't suitable for the longitudinal description of the dynamic changes of the efficiency in a period. Malmquist index can be used to make the evaluation of efficiency of china's Cultural Manufacturing Industries more detailed and comprehensive.

According to the empirical results in table 4.2, the following findings are summarized and discussed. First, the average Malmquist index of the 31 provincial Cultural Manufacturing Industries from 2012to2014 is 1.009 , greater than 1 , which means the overall efficiency of China's Cultural Manufacturing Industries is rising. The overall efficiency during the period of 2012-2013 and 2013-2014 are all rising. In addition, the differences of provincial TFP growth are significant. From 2012to 2014, the average growth rate of Heilongjiang province is highest and the average growth rate of Qinghai province is lowest. The TFP index of 6 regions is less than land 25 regions' TFP index is greater than 1 . The overall improved efficiency of 31 provincial Cultural Manufacturing Industries is due to the increase of the efficiency progress (effch) and the technical change (tech). From a technical change (tech) viewpoint, In addition to Hunan, Hainan and Qinghai, the average technology change index of other provinces and cities is greater than 1. Technical change has also been the decisive factor to the growth of efficiency; from a pure technical efficiency change (pech) viewpoint, more than half of regions' pech index is greater than 1 , the improvement of pure technical efficiency has been the important factor to the development of china's Cultural Manufacturing Industries; from a scale efficiency (sech) viewpoint, most of regions' scale efficiency index is less than 1, this illustrates that the scale efficiency of China's Cultural Manufacturing Industries is decreasing. Returns to scale has become the main factors influencing the efficiency of China's Cultural Manufacturing Industries.

Table 4.2 The Malmquist Index score of provincial Cultural Manufacturing Industries during

\begin{tabular}{cccccc}
\multicolumn{7}{c}{ 2012-2014 } & & & \\
\hline Region & effch & tech & pech & sech & tfp \\
\hline Beijing & 0.907 & 1.103 & 0.96 & 0.945 & 1.001 \\
Tianjin & 0.888 & 1.139 & 1 & 0.888 & 1.011 \\
Hebei & 0.949 & 1.099 & 0.997 & 0.952 & 1.043 \\
\hline
\end{tabular}




\begin{tabular}{|c|c|c|c|c|c|}
\hline Con Tab.4.2 & & & & & \\
\hline Shanxi & 0.929 & 1.069 & 0.924 & 1.006 & 0.994 \\
\hline Inner Mongolia & 1 & 1.072 & 1 & 1 & 1.072 \\
\hline Liaoning & 0.792 & 1.134 & 0.86 & 0.921 & 0.898 \\
\hline Jilin & 0.953 & 1.14 & 0.99 & 0.963 & 1.086 \\
\hline Heilongjiang & 1.265 & 1.033 & 1.31 & 0.965 & 1.306 \\
\hline Shanghai & 0.874 & 1.17 & 0.949 & 0.921 & 1.022 \\
\hline Jiangsu & 0.911 & 1.125 & 1 & 0.911 & 1.025 \\
\hline Zhejiang & 0.907 & 1.142 & 0.973 & 0.931 & 1.035 \\
\hline Anhui & 0.905 & 1.105 & 0.961 & 0.942 & 1.001 \\
\hline Fujian & 1.017 & 1.036 & 1.017 & 1 & 1.053 \\
\hline Jiangxi & 0.97 & 1.065 & 1.007 & 0.963 & 1.032 \\
\hline Shandong & 0.923 & 1.146 & 1 & 0.923 & 1.058 \\
\hline Henan & 0.953 & 1.081 & 0.98 & 0.972 & 1.03 \\
\hline Hubei & 1.029 & 1.102 & 1.077 & 0.956 & 1.135 \\
\hline Hunan & 1 & 0.947 & 1 & 1 & 0.947 \\
\hline Guangdong & 0.973 & 1.055 & 1 & 0.973 & 1.026 \\
\hline Guangxi & 1.073 & 1.005 & 1.076 & 0.997 & 1.078 \\
\hline Hainan & 1.148 & 0.999 & 1.144 & 1.004 & 1.148 \\
\hline Chongqing & 0.827 & 1.133 & 0.91 & 0.909 & 0.937 \\
\hline Sichuan & 1.049 & 1.063 & 1.034 & 1.014 & 1.115 \\
\hline Guizhou & 0.972 & 1.114 & 0.947 & 1.027 & 1.083 \\
\hline Yunnan & 0.967 & 1.121 & 1.027 & 0.942 & 1.084 \\
\hline Xizang & 0.858 & 1.09 & 1 & 0.858 & 0.936 \\
\hline Shaanxi & 1.054 & 1.109 & 1.106 & 0.953 & 1.169 \\
\hline Gansu & 0.927 & 1.047 & 0.962 & 0.963 & 0.97 \\
\hline Qinghai & 0.829 & 0.994 & 0.794 & 1.045 & 0.825 \\
\hline Ningxia & 0.91 & 1.133 & 0.962 & 0.945 & 1.031 \\
\hline Sinkiang & 0.905 & 1.115 & 1.022 & 0.886 & 1.009 \\
\hline Average score of eastern provinces & 0.950 & 1.101 & 1.004 & 0.945 & 1.042 \\
\hline Average score of Central provinces & 0.964 & 1.061 & 0.9915 & 0.973 & 1.023 \\
\hline Average score of Western provinces & 0.948 & 1.083 & 0.987 & 0.962 & 1.026 \\
\hline Average score of Northeast provinces & 1.003 & 1.102 & 1.053 & 0.950 & 1.0967 \\
\hline 2012-2013 & 1.047 & 0.992 & 1.009 & 1.037 & 1.039 \\
\hline 2013-2014 & 0.867 & 1.187 & 0.983 & 0.882 & 1.029 \\
\hline
\end{tabular}

development of Cultural Manufacturing Industries, the government should continue to enlarge the pool of Cultural Manufacturing Industries insurance funds to satisfy people's needs of cultural products and services.

\section{References}

[1] Information on http://finance.sina.com.cn

[2] Zhang, Wen Jun. Comparison and Evaluation of the Equipment Manufacturing Industries in Central Region in China, Journal of Hunan Finance \& Economics University (2011).

[3] Yaveroglu, Idil Sayrac, and N. Donthu. Cultural Influences on the Diffusion of New Products, Journal of International Consumer Marketing Vol.14(4) (2002):49-63.

[4] Jassawalla, Avan R. Cultures That Support ProductInnovation Processes, Academy of Management Executive Vol.16(3) (2002):42-54

[5] Richard A. Peterson, and N. Anand. The Production of Culture Perspective, Annual Review of Sociology Vol.15(30) (2004):311-334.

[6] Taylor, T. D. The Changing Shape of the Culture Industry; or, How Did Electronica Music Get into Television Commercials, Television \& New Media Vol.8.(3) (2007):235-258.

The paper has introduced the method of related DEA model and Malmquist index and analyzed the inputs and outputs selection of 31 China's provincial Cultural Manufacturing Industries, measured the efficiency and the dynamic changes of the efficiency of 31 China's provincial Cultural Manufacturing Industries during the period of 2012-2014. Through the following analysis, the results show that the efficiency of China's Cultural Manufacturing Industries is not high, the efficiency of eastern provinces is the lowest from 2012 to 2014.The average efficiency cores of 31 provincial Cultural Manufacturing Industries are all less than 1, On the whole, the average Malmquist index of the 31 China's provincial Cultural Manufacturing Industries is greater than 1 , and the overall improved efficiency of 31 China's provincial Cultural Manufacturing Industries is due to the increase of effch and tech.

According to the results of efficiency evaluation, China shall emphasize technical progress and expand the scale of $R \& D$ investment. Because technological progress has the positive effect on upgrading or re-structuring the value chain of Cultural Manufacturing Industries; enlarging scales of Cultural Manufacturing Industries and getting scale economy are urgent for increasing our industrial

competent abilities as China has low technical progress efficiency; finally, the provincial department should further increases the financing support dynamics and optimize the environment for the

[7] Valentine, Jeremy. Rent and Political Economy in Culture Industry,Work. Journal of Cultural Economy Vol.7(2) (2013):194-208.

[8] Han Donglin, et al. Evaluation of Technological Innovation Efficiency of Cultural Manufacturing Industry in Central China, Science \& Technology Progress \& Policy (2016).

[9] Mao Ruiqiong. The Study on The Transformation Efficiency of China's Cultural Manufacturing Industries, Business Vol.31 (2016):291-291 .

[10] Charnes, A., W. W. Cooper, and E. Rhodes. Measuring the efficiency of decision making units, European Journal of Operational Research Vol.2(6) (1978):429-444.

[11] Lvchen, Zeng Wenbing. Research on The Relative Efficiency of Science and technology in China Based on DEA, Scientific Management Research Vol.2 (2014):101-104.

[12] Liu, Yang, et al. Research of China Cultural Listed Company's Total Factor Productivity., Research on Economics \& Management (2014).

[13] Gao Xuewu, li Shuming. The Development Trajectory, Phase Characteristics and Efficiency of China's Cultural Industry, Financial Research Vol.6 (2014) :36-43 